\title{
SHARP OPERATOR MEAN INEQUALITIES OF THE NUMERICAL RADII
}

\section{Hosna JAFARMANESH AND MARYAM KHOSRAVI}

Abstract. We present several sharp upper bounds and some extension for product operators. Among other inequalities, it is shown that if $0<m I \leqslant B^{*} f^{2}(|X|) B, A^{*} g^{2}\left(\left|X^{*}\right|\right) A \leqslant M I, f, g$ are non-negative continuous functions on $[0, \infty)$ such that $f(t) g(t)=t,(t \geqslant 0)$, then for all non-negative operator monotone decreasing function $h$ on $[0, \infty)$, we obtain that

$$
\left\|h\left(B^{*} f^{2}(|X|) B\right) \sigma h\left(A^{*} g^{2}\left(\left|X^{*}\right|\right) A\right)\right\| \leqslant \frac{m k}{M} h\left(\left|\left\langle\left(A^{*} X B\right) x, x\right\rangle\right|\right),
$$

As an application of the above inequality, it is shown that

$$
\omega\left(A^{*} X B\right) \leqslant \frac{m k}{M}\left\|B^{*} f^{2}(|X|) B ! A^{*} g^{2}\left(\left|X^{*}\right|\right) A\right\|,
$$

where, $k=\frac{(M+m)^{2}}{4 m M}$ and $\sigma$ is an operator mean s.t., $! \leqslant \sigma \leqslant \nabla$.

Mathematics subject classification (2020): Primary 47A63; Secondary 47A64.

Keywords and phrases: Numerical radius, operator norm, inequality, refine.

\section{REFERENCES}

[1] J. S. Aujla AND F. C. Silva, Weak majorization inequalities and convex functions, Linear Algebra Appl., 369 (2003), 217-233.

[2] T. ANDo AND F. HiaI, Operator log-convex functions and operator means, Math. Ann. 350 (2011), 611-630

[3] A. ABU-OMAR AND F. KitTANeH, A numerical radius inequality involving the generalized Aluthge transform, Studia Math. 216 (2013), 69-75.

[4] R. Bhatia, Matrix Analysis, Springer, NewYork (1997).

[5] S. S. DRAGOMIR, Power inequalities for the numerical radius of a product of two operators in Hilbert spaces, Sarajevo J. Math. 5 (18) (2) (2009) 269-278.

[6] H. Jafarmanesh, M. Khosravi And A. Sheikhhosseini, Some operator inequalities involving operator monotone functions, Bulletin des Sciences Mathematiques, 2021, doi:10.1016/j.bulsci.2020.102938.

[7] F. Kittaneh, Notes on some inequalities for Hilbert space operators, Publ. Res. Ints. Math. Sci., 1988, 24 (2): 283-293.

[8] F. KitTAneH, Norm inequalities for sums of positive operators, J. Operator Theory 48 (2002), 95103.

[9] F. Kittaneh, Numerical radius inequalities for Hilbert space operators, Studia Math. 1681 (2005), 73-80.

[10] B. Mond And J. Pecaric, On Jensen's inequality for operator convex functions, Houston J Math, 1995, 21: 739-753.

[11] K. Shebrawi And H. Albadawi, Numerical radius and operator norm inequalities, J. Inequal. Appl. 2009, Art. ID 492154, 11-pp.

[12] M. Sattari, M. S. Moslehian And T. YAmaZaki, Some generalized numerical radius inequalities for Hilbert space operators, Linear Algebra Appl, 470 (2014), 1-12.

[13] T. YAMAZAKI, On upper and lower bounds of the numerical radius and on equality condition, Studia Math. 178, (2007), 83-89. 